\title{
CONVERSE JENSEN INEQUALITY FOR STRONGLY CONVEX SET-VALUED MAPS
}

\section{Milica Klaričić BAKUla AND KAZIMieRZ NiKOdeM}

Abstract. Integral and discrete counterparts of the converse Jensen inequality for strongly convex set-valued maps are presented.

Mathematics subject classification (2010): Primary 26A51, Secondary 39B62, 54C60.

Keywords and phrases: Strongly convex functions, strongly convex set-valued map, Jensen inequality, converse Jensen inequality.

\section{REFERENCES}

[1] J.-P. Aubin, H. Frankowska, Set-Valued Analysis, Birkhäuser, Boston-Basel-Berlin, 1990.

[2] J. Diestel, J. J. Uhl, JR., Vector Measures, Amer. Math. Soc., Providence, 1977.

[3] H. HUANG, Global error bounds with exponents for multifunctions with set constraints, Communications in Contemporary Math. 12 (2010), 417-435.

[4] M. KlaRiČIĆ BAKULA, K. NiKODEM, On the converse Jensen inequality for strongly convex functions, J. Math. Anal. Appl. 434 (2016), 516-522.

[5] H. Leiva, N. Merentes, K. Nikodem And J. L. SÁnchez, Strongly convex set-valued maps, J. Glob. Optim. 57 (2013), 695-705.

[6] J. Matkows Ki, K. Nikodem, An integral Jensen inequality for convex multifunctions, Results Math. 26 (1994), 348-353.

[7] N. Merentes And K. Nikodem, Remarks on strongly convex functions, Aequationes Math. 80 (2010), 193-199.

[8] K. Nikodem, Strongly Convex Functions and Related Classes of Functions in: Th. M. Rassias (Ed.) Handbook of Functional Equations. Functional Inequalities, Springer Optimizations and Its Applications, vol. 95, 2015, 365-405.

[9] K. NiKODEM AND Zs. PÁLES, Characterizations of inner product spaces by strongly convex functions, Banach J. Math. Anal. 5 (2011), no. 1, 83-87.

[10] K. NikODEM, J. L. SÁnCHEZ, L. SÁNCHEZ, Jensen and Hermite-Hadamard inequalities for strongly convex set-valued maps, Math. Aeterna 4 (2014), 979-987.

[11] E. S. Polovinkin, Strongly convex analysis, Sbornik Mathematics 187/2 (1996), 103-130.

[12] B. T. POLYAK, Existence theorems and convergence of minimizing sequences in extremum problems with restrictions, Soviet Math. Dokl. 7 (1966), 72-75.

[13] T. RAJBA, Sz. W A̧SOWICZ, Probabilistic characterization of strong convexity, Opuscula Math. 31 (2011), 97-103.

[14] R. SCHULTZ, Strong convexity in stochastic programs with complete recourse, J. Comput. Appl. Math. 56 (1994), 3-22.

[15] J. P. VIAL, Strong convexity of sets and functions, J. Math. Economy 9 (1982), 187-205. 